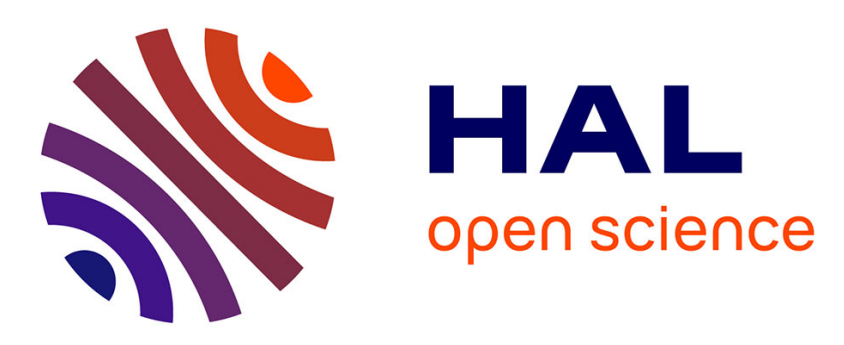

\title{
Morphology of Strategic Components for Data-Driven Industrial Services
}

Günther Schuh, Dominik Kolz

\section{To cite this version:}

Günther Schuh, Dominik Kolz. Morphology of Strategic Components for Data-Driven Industrial Services. IFIP International Conference on Advances in Production Management Systems (APMS), Sep 2017, Hamburg, Germany. pp.214-221, 10.1007/978-3-319-66926-7_25 . hal-01707293

\section{HAL Id: hal-01707293 \\ https://hal.inria.fr/hal-01707293}

Submitted on 12 Feb 2018

HAL is a multi-disciplinary open access archive for the deposit and dissemination of scientific research documents, whether they are published or not. The documents may come from teaching and research institutions in France or abroad, or from public or private research centers.
L'archive ouverte pluridisciplinaire HAL, est destinée au dépôt et à la diffusion de documents scientifiques de niveau recherche, publiés ou non, émanant des établissements d'enseignement et de recherche français ou étrangers, des laboratoires publics ou privés.

\section{(c)(1)}

Distributed under a Creative Commons Attribution| 4.0 International License 


\title{
Morphology of Strategic Components for Data-Driven Industrial Services
}

\author{
Günther Schuh and Dominik Kolz \\ Institute for Industrial Management (FIR), Campus-Boulevard 55, 52074 Aachen, Germany \\ Günther.Schuh@fir.rwth-aachen.de, \\ Dominik.Kolz@fir.rwth-aachen.de
}

\begin{abstract}
The design of data-driven industrial services in the context of industry 4.0 represents a major challenge for industrial service providers and manufacturing companies for investment goods. Data-driven services require technological and strategic components that most companies have not build up yet and that differ from current configurations. That is why many companies lack a systematic approach and implementation competence for the use of data in the context of industrial services and therefore face the challenge of not being able to expand their market position in an ever-growing competition for data. The present paper addresses this research deficit with the aim of describing strategic features and characteristics of data-driven industrial services by identifying the related crucial features and characteristics through a morphological approach. This will enable industrial service providers to improve strategic and operative management decisions in order to define a specific strategy and to configure data-driven services.
\end{abstract}

Keywords: Industrial services, data-driven services, morphology

\section{Introduction}

Within the last 50 years, information technologies have changed the way companies conduct their business more than once: The rise of the computer in the 60s led to automation within value chains and raised awareness on the use of data. Afterwards in the 80 s, the internet allowed real-time collaboration, facilitated global supply chains and boosted the generation and usage of data. The next transformation, the internet of things, has already started and impacts competition and strategy like none before. [1, 2]

Parallel to that development, companies underwent a transformation process, developed from product manufactures to solution providers, and thus generate additional value for their customers. In practice, it can be observed that companies follow this transformation process, but the offering of operating models and output-based solutions is not established extensively: Service level agreements and output-oriented business models are offered by only $18 \%$, respectively $13 \%$, of global industrial companies. [3] 
This can be attributed to the relatively low usage of data that enables companies to learn from their products, learn from their customers and adapt their products and services to the needs of their customers. [4, 5]

\section{Objective of developing a morphology}

The use of data and big data in an industrial context is mainly driven by quality improvements and the resulting reduction in the frequency of errors and process efficiency improvements. Process engineers use enormous amounts of data to control, monitor, and optimize the performance of processes. [6]

Although premium manufacturers have a high digital competitiveness and therefore the best conditions to compete in a data-driven world, they often fail to develop databased value-added services [7, 8]. This can be attributed to the following practical problems: Most industries are lagging behind the chances and potentials of digital transformation. Decision-makers focus on the realization of internal potentials first, such as cost savings through technology use or cost reduction through more standardized service processes. However, the realization of potentials driven by innovations is largely neglected. This includes the use of data-based services to increase revenues. [4, 9] The same applies for the scientific research gap: Previous approaches dealing with digitalization, data-based business models, and digital driven services mostly describe case studies or individual characteristics of data-based services, but lack the provision of a detailed description, based on detailed features and characteristics (Table 1). In summary, there is a lack of a scientifically based, illustrative and practical systematization of industrial, data-based services.

In order to describe data-driven services, the following definition is used in this paper: Data-based services are intelligent, internet-based services. They are either linked to physical products as data providers and in doing so complement the products, or are based on data-driven services that are detached from products. Smart services are datadriven services based on digital platforms that enable the formation of service ecosystems in which different actors are organized. [7, 10, 11, 12]

\section{Theoretical Foundation}

The report of the working group "Smart Service Welt - Internet-based Services for the Economy" by Acatech represents a fundamental conceptual basis for the present paper. The scope of the report lies within the linking of processes, products and services with data. This connection is seen as the most important basis for the development of new services and business models. The developed layer model schematically describes the composition of digital infrastructures for smart service delivery in four levels: smart spaces, smart products, smart data and smart services. In accordance to the layer model of digital infrastructures, the following components are utilized in order to develop a morphology for strategic components of data-driven, industrial services: collect data, data transfer and backup, analyze data and service delivery. [13] 
Morphology of Strategic Components for Data-Driven Industrial Services 3

Besides this fundamental work by Acatech, a literature review has been conducted. In Table 1, an extract of the central scientific approaches for the elaboration of this paper is listed. Previous research deals with technical or strategic components in the field of data-based-services, the internet of things, big data and analytics, business intelligence and business models. Regarding this research, features, classifications, morphologies and typings are developed. However, none of the previously conducted research delivers a consolidated morphology of strategic and technical features for databased-services.

Table 1. Literature review (Harvey Balls: meets the criterion/ partially meets the criterion)

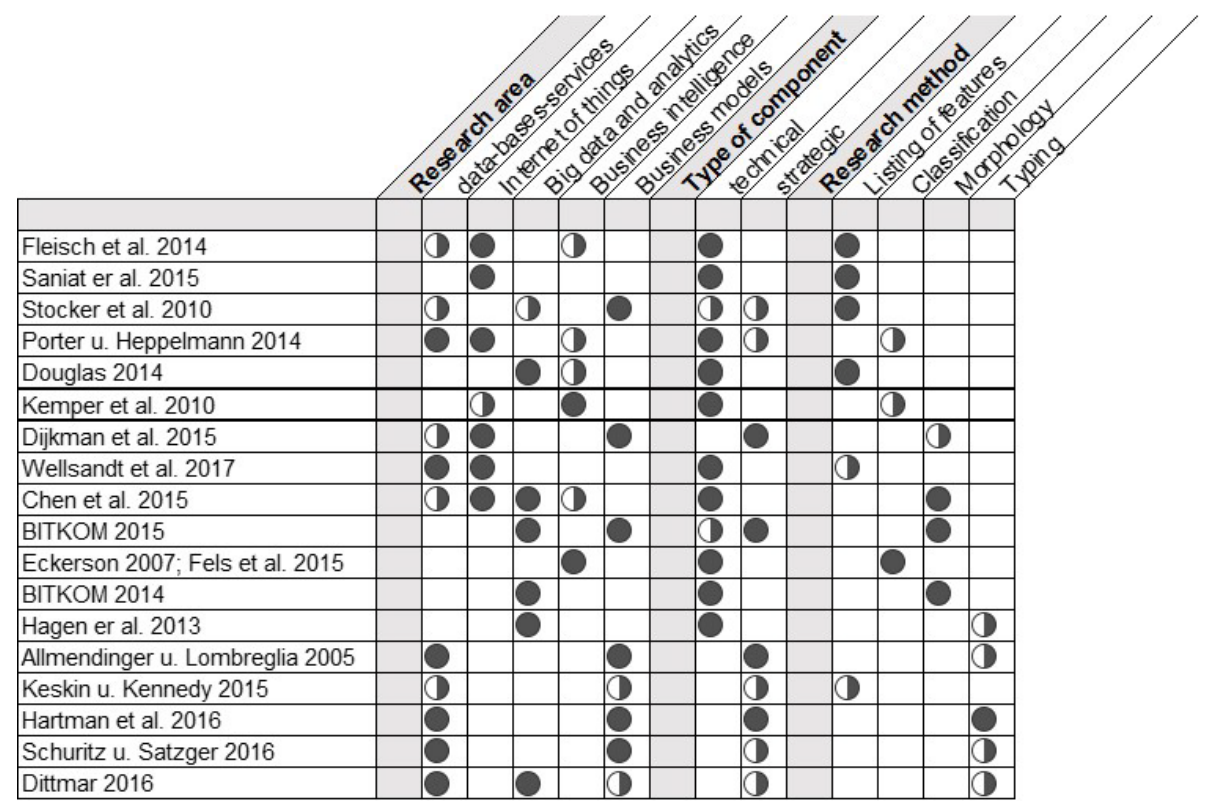

\section{$4 \quad$ Methodology}

Analytical research methods, such as classification, morphological methods or typing, are used to gain insights into research objects. They contribute decisively to generating new knowledge on investigation objects. According to the aim of the paper of describing the main strategic components of data-driven industrial services, the morphological method is particularly suitable, since the construction of a morphological box allows the derivation of multi-dimensional solutions to describe real situations with features and characteristics. The following procedure, consisting of three consecutive steps was conducted in alignment with a research approach following Zwicky [14] and Welter [15]:

1) Definition of the test area: The formation of types starts with the analysis of the test area and the identification of the objects to be examined. 
2) Selection of suitable features: After the definition of the test area, the features are identified, with regard to the research objective. These features can be descriptive or type-forming. Type-forming features are constitutive and define a type, while descriptive features build up a type. Characteristics of features can be distinguished in polar or scalable. If characteristics are discrete, assuming real values (e.g. company size); they are called polar features, while gradual characteristics (e.g. temperature) that can be described by an infinite number of characteristics are named scalable characteristics.

3) Determination of meaningful characteristics: After the selection of appropriate features, the design of the corresponding characteristics is carried out. This is done by means of qualitative and quantitative descriptions of the subject of the investigation.

\section{Morphology of strategic features and characteristics of data- driven industrial services}

Below, the features of the morphology are briefly described. In order to develop and offer data-driven services, companies need to consider the following components, derived from the layer model of digital infrastructures [13]: Collect data, data transfer and backup, analyze data and service delivery. Following the morphological approach, the strategic features and characteristics depicted in Figure 1 have been identified.

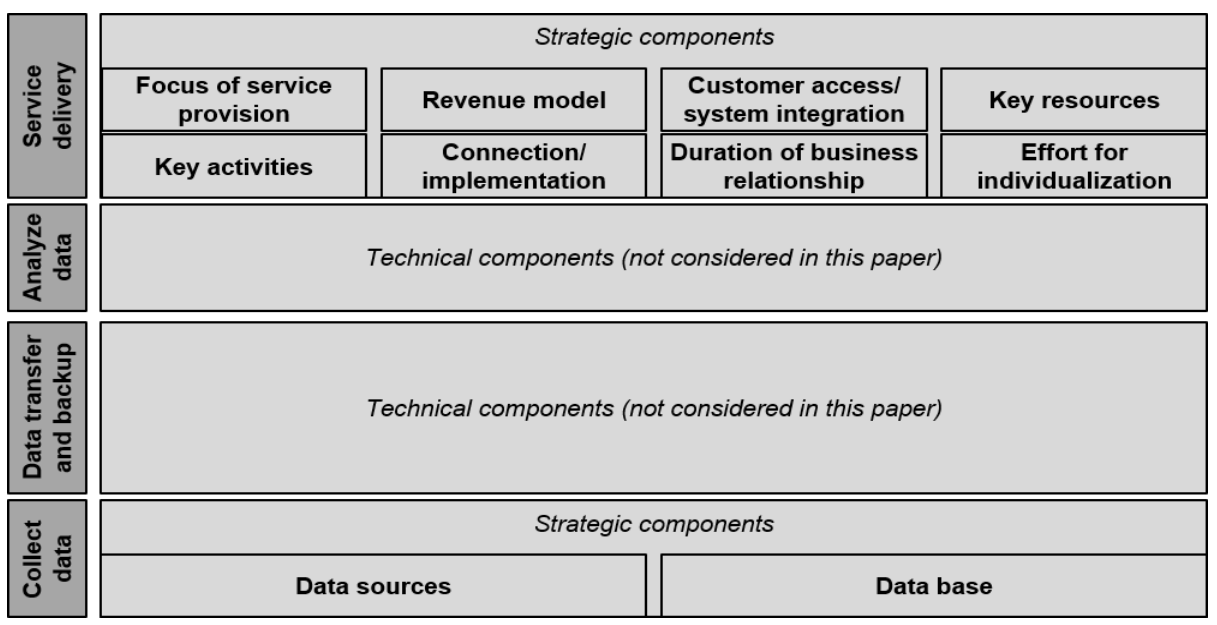

Fig. 1. Overview of strategic components of data-driven industrial services

Service delivery.

The Focus of service provision describes an object-oriented, value-chain-oriented or ecosystem oriented approach. In case of the object-oriented focus, own objects, foreign objects or both, own and foreign objects can be distinguished. [6]

The feature Key activities consist of the virtual and physical provision of services. The virtual provision consists of the characteristics of the provision of raw data and the 
provision of knowledge. [16] An additional step lies within the virtual provision of services as the orchestration within a supply chain or ecosystem. The physical provision of services is based on the characteristics of the provision of services by the provider itself, or the provision by a third party.

The Revenue model for data-driven industrial services can be divided into three characteristics: Free add-on to an object, individual billing and performance related billing. The last characteristic can be divided into pay-per use, pay on availability and pay on production. $[17,18]$

The feature Connection and implementation is depicted through two main characteristics and describes the effort for implementation as purely administrative or physical. A purely administrative implementation occurs, when the object is already connected to the internet and a connection to the provider is established similar to plug and play. In case of a physical connection, objects and systems have to be connected to each other. This physical connection can be established by the customer itself, by the provider or by a third party.

The feature Key resources consists of physical resources such as plants and equipment, properties, machines, systems and spare parts. Intellectual resources are brands, knowledge, copyrights and the partner network. $[16,19,8]$ In this case, the partner network is viewed as a separate characteristic.

The Effort for individualization describes the companies' effort, in order to provide standardized or customer-specific services. For this reason, the following characteristics are used: combination of standardized services, individually adapted services by occasion and customer-specific generation of overall services. [17]

The Customer access and system integration is described by four main characteristics. The first characteristic describes the access to a service through manual channels (e-mail, USB-sticks, etc.), followed by the provision of services through the system of the provider. This could be a web-portal or a software that is distributed to the customer in order to deliver dashboards and visualizations. A deeper integration is achieved through the link into the customers' existing ERP or PLM system. The fourth characteristic describes platforms that can be closed (operated and organized by a single company) or open (provision of a technological basis that enables collaboration between different players) [13].

The Duration of business relationship can be divided into three characteristics. Short-term (single transaction), medium-term ( $<2$ yrs.) and long-term ( $>2$ yrs.) [20].

Data transfer and backup and Analyze data.

The components Data transfer and backup and Analyze data have no overall strategic importance. Following this paper, further research will be conducted for these technical components, including for example the capability for data exploitation, data query, data quality management or method of data analysis.

\section{Collect Data.}

Data sources can be divided into internal and external data. Internal data itself can be divided into several data sources: data that exists or is created in IT-systems, but that is not used and data that is, among others, generated for a certain purpose through web 
tracking, physical devices, crowdsourcing and social collaboration methods. External data uses acquired data that is purchased, or provided by customers. [16]

The Data base consists of multiple steps. At first, data of a single object is considered. This is expanded by the view of aggregated object data of a single customer. The next steps focus on aggregated object data of several customers or aggregated data of a value chain. The last characteristic is aggregated data of an ecosystem.

The developed morphology helps service providers and manufactures to position themselves strategically by combining different characteristics. The validity of the developed morphology, consisting of strategic components of data-driven industrial services has been confirmed in several company workshops and expert discussions. The development of different types of data-driven industrial services represents a downstream research work and a logical next step. A possible type formation is briefly explained below.

Morphology of strategic features and characteristics of data-driven industrial services. Figure 2 shows the developed features and characteristics in accordance to the morphological approach.

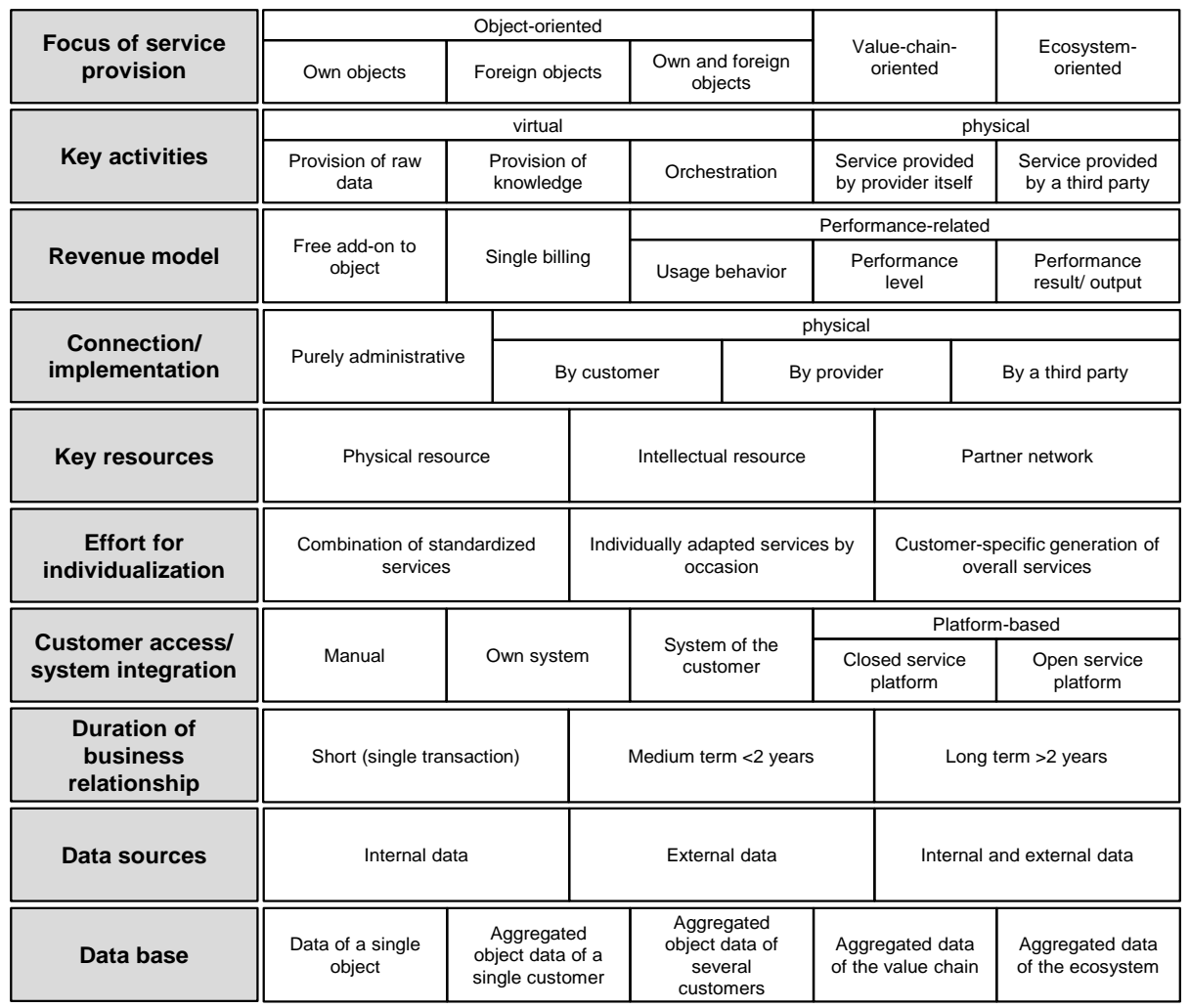

Fig. 2. Strategic components of data-driven industrial services 
Knowledge as add-on to own objects: This type focuses on own objects. However, the raw data obtained through the object is transformed to information and knowledge through data analysis methods. In this case, it is no longer merely a matter of a dashboard for visualizing raw data, but rather the individual provision of customer-specific recommendations for machine optimization or use, comparable to a remote consulting service. The vendor is able to provide this knowledge since he can access aggregated object data of many customers through the installed base, create comparability and generate specific knowledge about the use and improvement of the object. Access to the data is important; however the intellectual ability to draw conclusions from data is a key resource. The billing of the virtual service is performed individually and the service is delivered virtually. Since the vendor only supports the customer with specific services on a selective basis, the service is based on one or more individual transactions.

\section{Conclusion and Outlook}

The scientific result of this paper is a morphology for strategic components of datadriven industrial services. The morphology depicts a detailed summary of strategic components for data-driven industrial services based on data collection and service delivery. The results enable strategic and operative decision makers to align the future service portfolio and configure data-driven services for individual domains. Therefore, the scientific result of this paper closes the previously stated research gap. Further research may be conducted in order to develop technical components of data-driven industrial services. These results will be developed in the follow-up to this paper and in accordance with the developed regulatory framework, especially with regard to data transfer and backup and data analysis. In addition, the model will have to be validated by industrial users.

\section{$7 \quad$ References}

1. Porter, M. E., Heppelmann, J. E.: How smart, connected products are transforming competition. Harvard business review: vol. 92 (11), pp. 64-88 (2014)

2. Keskin, T., Kennedy, D.: Strategies in Smart Service Systems Enabled Multi-sided Markets. Business Models for the Internet of Things. In: 2015 48th Hawaii International Conference on System Sciences, pp. 1443-1452. IEEE Press, New York (2015)

3. Baines, T.: Proving the Service Continuum: Quantifying the strategic and economic impact of global service transformation. Oxford Economics, https:/www.ptc.com/ /media/Files/PDFs/SLM/Professor-Tim-Baines-on-Oxford-Economics--study-Proving-theService-Continuum.ashx?la=en

4. Husmann, M., Fabry, C.: „Smart Services - Neue Chance für Services ,Made in Europe‘KVD-Servicestudie. Aachen (2014)

5. Dijkman, R. M., Sprenkels, B., Peeters, T., Janssen, A.: Business models for the Internet of Things. In: International Journal of Information Management, vol. 35, no. 2, pp. 672-678. (2015)

6. Yin, S., Kaynak, O.: Big Data for Modern Industry: Challenges and Trends Proc. IEEE, vol. 103, pp. 143-146. New York (2015) 
7. Smart Service Welt Working Group, acatech - National Academy of Science and Engineering: Smart Service Welt. Recommendations for the Strategic Initiative Web-based Services for Businesses. Interim Report (2014)

8. Kagermann, H.: IT-driven business models. Global case studies in transformation. John Wiley \& Sons, Hoboken, N.J (2011)

9. Marr, B.: Big data. Using smart big data, analytics and metrics to make better decisions and improve performance. Wiley, Chichester (2015)

10. Herterich, M., Uebernickel, F., Brenner, W.: The Next Wave of Service Innovation: How cyber-physical systems can be leveraged for effective industrial equipment operations and empower industrial service. Report. IWI-HSG, St. Gallen (2015)

11. Brownlow, J., Zaki, M., Neely, A., Urmetzer, F.: Data-Driven Business Models: A Blueprint for Innovation. University of Cambridge, Cambridge Service Alliance, http://cambridgeservicealliance.eng.cam.ac.uk/resources/Downloads/Monthly\%20Papers/2015FebruaryPaperTheDDBMInnovationBlueprint.pdf

12. Chae, B.: Big Data and IT-Enabled Services - Ecosystem and Coevolution. IT Professional vol. 17, issue 2, pp. 20-25, IEEE (2015)

13. Smart Service Welt Working Group, acatech - National Academy of Science and Engineering: Smart Service Welt. Recommendations for the Strategic Initiative Web-based Services for Businesses. Final Report Long Version (2015)

14. Zwicky, F.: Entdecken, Erfinden, Forschen im Morphologischen Weltbild. Droemer/Knaur, München (1966)

15. Welter, M.: Die Forschungsmethode der Typisierung: Charakteristika, Einsatzbereiche und praktische Anwendung WiSt - Wirtschaftswissenschaftliches Studium 35(2), Franz Vahlen and C.H. Beck, München and Frankfurt (2006)

16. Hartmann, P. M., Zaki, M., Feldmann, N., Neely, A.: Big Data for Big Business? A Taxonomy of Data-driven Business Models used by Start-Up Firms. Hg. v. University of Cambridge. Cambridge Service Alliance. Cambridge, http://www.nemode.ac.uk/wp-content/uploads/2012/12/2014_March_Data-Driven-Business-Models.pdf

17. Ansorge, B.: Ordnungsrahmen für die Positionierung industrieller Dienstleister. Techn. Hochschule, 1st edn. Schriftenreihe Rationalisierung, vol. 129. Apprimus-Verlag, Aachen (2014)

18. Nagle, T., Hogan, J.: The strategy and tactics of pricing. A guide to growing more profitably. 4th edition, Pearson/Prentice Hall, Upper Saddle River, NJ (2006)

19. Schuh, G., Gudergan, G.: Einführung und Grundlagen des Managements industrieller Dienstleistungen. In: Schuh, G., Gudergan, G., Kampker, A. (eds) Management industrieller Dienstleistungen: Handbuch Produktion und Management 8, 2nd edn. VDI-Buch, pp. 1-19. Springer Berlin Heidelberg, Berlin, Heidelberg (2016)

20. Weber, C., Steinbach, M., Botta, C.: Properties and Characteristics of Product-Service Systems - An integrated View. NordDesign 2004, Tampere, Finland (2004) 